\title{
Anisotropic Thin Composite Bonded Magnets Prepared by Compaction Using the Slip-Flow Phenomenon
}

\author{
Fumitoshi Yamashita $^{1}$ and Hirotoshi Fukunaga ${ }^{2}$, Member, IEEE \\ ${ }^{1}$ Motor R\&D Laboratory, Matushita Electric Industrial Company, Ltd., Osaka 574-0044, Japan \\ ${ }^{2}$ Faculty of Engineering, Nagasaki University, Nagasaki 852-8521, Japan
}

\begin{abstract}
Thin composite bonded magnets, $400 \mathrm{im}$ in thickness and $140 \mathrm{~kJ} / \mathrm{m}^{3}$ in $(\mathrm{BH})_{\max }$ under a low compacting pressure such as $20 \mathrm{MPa}$, were achieved by using the slip-flow phenomenon for self-organization of binder. The mechanical strength of the prepared composite bonded magnets was not deteriorated by thinning, which enabled the preparation of magnets for transformation into smaller radially anisotropic ones.
\end{abstract}

Index Terms-Bonded magnet, HDDR-Nd-Fe-B, radially anisotropic, RD-Sm-Fe-N, self-organization.

\section{INTRODUCTION}

A LTHOUGH use of anisotropic $\mathrm{Nd}_{2} \mathrm{Fe}_{14} \mathrm{~B}$ powder made by the hydrogenation, disproportionation, desorption, and recombination (HDDR) process is one of the promising methods of preparing magnets for small motors beyond conventional isotropic $\mathrm{Nd}_{2} \mathrm{Fe}_{14} \mathrm{~B}$ bonded magnets. However, magnetic properties of radially oriented anisotropic ring-shaped magnets are deteriorated when their alignment degree is decreased for miniaturization, resulting in the fabrication of smaller motors with high mechanical output, becomes difficult. Furthermore, magnetic stabilities of the above-mentioned anisotropic magnets were worse than that of isotropic magnets. Previously, a new technique using self-organization of binder, which enabled the alignment of macromolecular chain among crosslink points, was developed, and, consequently, their difficulty was overcome. By using this technique, the authors controlled the flexibility of rigid sheet magnets with the thickness of approximately $0.85-1.35 \mathrm{~mm}$, transformed them into various shapes, and succeeded in preparing ring/arc-shaped bonded magnets [1]-[3]. In this study, the slip-flow phenomenon in addition to the above-mentioned technique was used, and anisotropic thin composite bonded magnets were successfully prepared for transformation into radially anisotropic ones. In the developed technique, composite bonded magnets with HDDR $-\mathrm{Nd}_{2} \mathrm{Fe}_{14} \mathrm{~B}$ particles and reduction and diffusion (RD)- $\mathrm{Sm}_{2} \mathrm{Fe}_{17} \mathrm{~N}_{3}$ ones were obtained typically under an elevated temperature of $160{ }^{\circ} \mathrm{C}$, an axially alignment field of $1.4 \mathrm{MA} / \mathrm{m}$, and a low compacting pressure of $20-50 \mathrm{MPa}$. The developed magnets kept their mechanical strength even when their thickness decreased, and their $(\mathbf{B H})_{\max }$ value depended only on the density. Consequently, the obtained magnets are expected to enable further miniaturization of small motors.

\section{EXPERIMENT}

\section{A. Materials}

HDDR $-\mathrm{Nd}_{2} \mathrm{Fe}_{14} \mathrm{~B} \quad[53-150 \mu \mathrm{m}$ in particle size and $300 \mathrm{~kJ} / \mathrm{m}^{3}$ in $\left.(\mathbf{B H})_{\max }\right]$ and $\mathrm{RD}-\mathrm{Sm}_{2} \mathrm{Fe}_{17} \mathrm{~N}_{3}[2-3 \mu \mathrm{m}$ in particle size and $295 \mathrm{~kJ} / \mathrm{m}^{3}$ in $(\mathbf{B H})_{\max }$ ] were used as starting materials. Solid epoxy-oligomer, polyamide-12 including an adhesive agent, and imidazole-adduct for chemical contact were also used for the self-organization of binder. In addition, four kinds of additives were selected for improvement in the flowability of the compound.

\section{B. Preparation Processes}

At first, RD- $\mathrm{Sm}_{2} \mathrm{Fe}_{17} \mathrm{~N}_{3}$ powder $(38.20$ wt.\%) and HDDR $-\mathrm{Nd}_{2} \mathrm{Fe}_{14} \mathrm{~B}$ one (57.44 wt.\%) were coated with epoxy-oligomer $(1.00$ wt.\%). Subsequently, polyamide (2.80 wt.\%), four kinds of additive (0.28 wt.\%), and epoxycoated powder $(96.64 \mathrm{wt} . \%)$ were mixed under the molten state of binder. During mixing, pentaerythritol-stearic-tri-ester $\left(\mathrm{HO}-\mathrm{CH}_{2}\right)-\mathrm{C}-\left[\mathrm{OOC}-\left(\mathrm{CH}_{2}\right)_{16} \mathrm{CH}_{3}\right]_{3}$, glycerin-behenicmono-ester $\mathrm{HO}-\mathrm{CH}_{2} \mathrm{CH}(-\mathrm{OH})-\mathrm{CH}_{2} \mathrm{OOC}-\left(\mathrm{CH}_{2}\right)_{20} \mathrm{CH}_{3}$, stearil-di-ester $\quad \mathrm{CH}_{3}\left(\mathrm{CH}_{2}\right)_{16}-\mathrm{COO}-\left(\mathrm{CH}_{2}\right)_{16} \mathrm{CH}_{3}$, or stearil-alcohol $\mathrm{HO}-\left(\mathrm{CH}_{2}\right)_{16} \mathrm{CH}_{3}$ was added to the compound and the resultant compounds were denoted by compounds $\mathrm{I}_{\mathrm{a}}$, $\mathrm{I}_{\mathrm{b}}, \mathrm{I}_{\mathrm{c}}$, and $\mathrm{I}_{\mathrm{d}}$, respectively. Then, the particle size of all the granular compounds was adjusted to $350 \mu \mathrm{m}$ or less by crushing and sieving classification. On the other hand, compound II, which did not contain an additive, was also prepared for comparison. In the final step of the compounding, imidazole-adduct $(0.28$ wt.\%) was dry blended to all the compounds.

Next, an obtained compound, $5 \mathrm{~g}$ in weight, was compacted into a disc-shaped magnet under a pressure of 20-50 MPa at an elevated temperature of $150-160{ }^{\circ} \mathrm{C}$. At that time, two kinds of magnetic powder in a compound were aligned by applying a magnetic field of $1.4 \mathrm{MA} / \mathrm{m}$ during compaction as shown in Fig. 1. The dimensions of the obtained magnets were less than $70 \mathrm{~mm}$ in diameter and approximately $400-1350 \mu \mathrm{m}$ in thickness. Then, the prepared magnets were heated at $180{ }^{\circ} \mathrm{C}$ for 


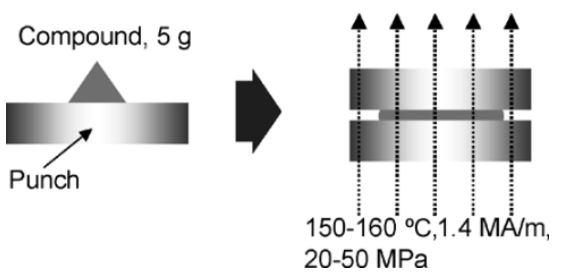

Fig. 1. Schematic representation of the preparation process of a thin composite bonded magnet compacted under an elevated temperature and an alignment field.

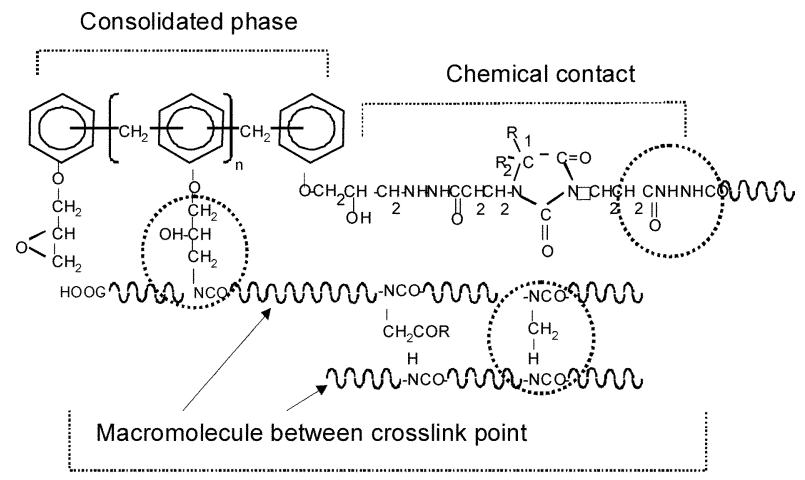

Molecular chain alignment phase

Fig. 2. Chemical structure of the self-organized binder, which is fabricated by means of a crosslinking reaction. Dotted circles indicate the estimated chemical structures of the chemical contact points.

20 min for self-organization of binder. As a result, the macromolecular chain among crosslink points would be synthesized, and it was estimated as shown in Fig. 2. The flexibility of the obtained magnets can be controlled by the same method reported previously [1]-[3].

The properties of flowability, compactibility, tensile strength, density, magnetic properties, and morphology were evaluated.

\section{RESULTS AND DISCUSSION}

\section{A. Flowability and Compactibility}

Fig. 3(a) and (b) shows the relation between the melt viscosity of base binder including additives and (a) the flowability of the compounds and (b) the tensile strength of their magnets. Comparing with compound II, the melt viscosity of the base binder of compounds $\mathrm{I}_{\mathrm{b}}, \mathrm{I}_{\mathrm{c}}$, and $\mathrm{I}_{\mathrm{d}}$ decreased, and their flowability (disc flow) was kept at low levels. On the other hand, the flowability of compound $I_{a}$ was improved remarkably with the increase in the melt viscosity as shown in Fig. 3(a). Furthermore, the decrease in the tensile strength of compound $\mathrm{I}_{\mathrm{a}}$ was little, compared with the other compounds including additives (compounds $\mathrm{I}_{\mathrm{b}}, \mathrm{I}_{\mathrm{c}}$, and $\left.I_{d}\right)$ as shown in Fig. 3(b). Compound $I_{a}$ includes one hydroxyl group, $-\mathrm{OH}$, for the good solubility to binder and three alkyl groups, $-\left(\mathrm{CH}_{2}\right)_{16} \mathrm{CH}_{3}$, for lubricants, and it is expected to have a strong elution characteristic during the heating and compaction process. As a result, the slip-flow phenomenon was observed significantly for compound $\mathrm{I}_{\mathrm{a}}$ at $160{ }^{\circ} \mathrm{C}$.

The density of the composite bonded magnet is shown in Fig. 4 as a function of the compacting pressure for compounds $\mathrm{I}_{\mathrm{a}}$ and II. For compound II, a highly dense magnet was obtained under a pressure at $50 \mathrm{MPa}$. On the other hand, a high density was achieved under the pressure of $20 \mathrm{MPa}$ for compound

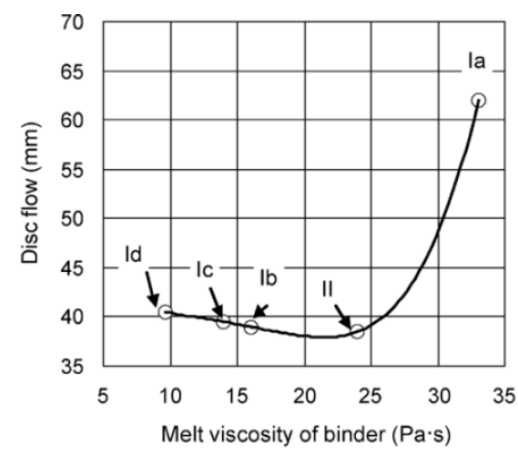

(a)

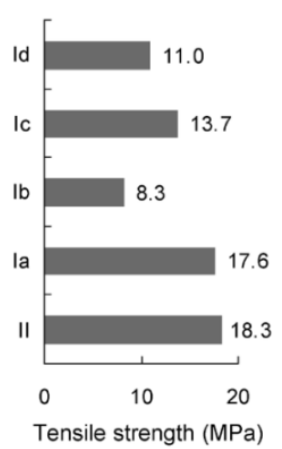

(b)
Fig. 3. Relation between the melt viscosity of base polyamide binders and (a) the flowability (disc flow) of their compounds and (b) the tensile strength of obtained magnets after heating at $180^{\circ} \mathrm{C}$ for $20 \mathrm{~min}$. Flow rate of the compounds was tested by using JIS K-6911 disc flow test (5 g in weight, $160^{\circ} \mathrm{C}$ in measuring temperature, and $500 \mathrm{kN}$ in pressure [4]). Melt viscosity was tested by using rotational viscometer at $160^{\circ} \mathrm{C}$.

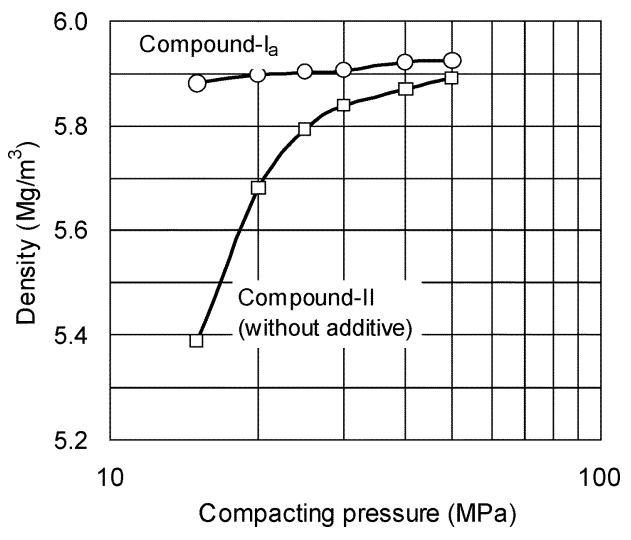

Fig. 4. Density of magnet as a function of compacting pressure. Compacting temperature was set at $160^{\circ} \mathrm{C}$.

$\mathrm{I}_{\mathrm{a}}$. This pressure is approximately $2.5 \%$ of that needed for the preparation of anisotropic $\mathrm{Nd}_{2} \mathrm{Fe}_{14} \mathrm{~B}$ bonded magnets by the conventional compaction method [5]. A small pressure required for compound $\mathrm{I}_{\mathrm{a}}$ can be attributed to the fact that the self-organization of binder exhibits the slip-flow phenomenon as shown in Fig. 3(a). The density and relative density of the magnets prepared from compound $I_{a}$ under a low pressure of $20 \mathrm{MPa}$ exceeded $5.9 \mathrm{Mg} / \mathrm{m}^{3}$ and $98 \%$, respectively, when the self-organization binder concentration was approximately $4 \mathrm{wt} . \%$ as shown in Fig. 4.

Consequently, the magnets prepared from compound $\mathrm{I}_{\mathrm{a}}$ had the highest density in the magnets shown in Fig. 3, and the density of radially oriented anisotropic composite bonded magnets was the highest in any rare-earth flexible bonded magnets known up to now. In addition, the utilization of compound $\mathrm{I}_{\mathrm{a}}$ enabled us to use stainless steel or carbon steel instead of hard alloy as a material for punches. Thus, we can conclude that compound $I_{a}$ exhibits good compactibility with the assistance of the slip-flow phenomenon, and that this phenomenon can be attributed to the additive based on the balance between hydroxyl group and alkyl groups.

\section{B. Magnetic Properties and Morphology}

Fig. 5 shows the dependence of the density on $(\mathbf{B H})_{\max }$ of composite bonded magnets fabricated from compounds $I_{a}$ and 


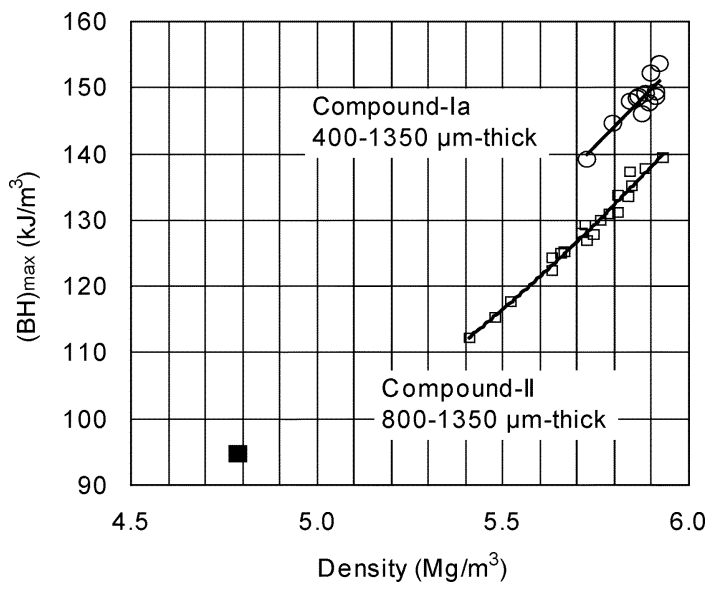

Fig. 5. Density dependency of $(\mathbf{B H})_{\max }$ of composite bonded magnets prepared from compound $\mathrm{I}_{a}$ together with that of magnets prepared from compound II and that of an $\mathrm{Sm}_{2} \mathrm{Fe}_{17} \mathrm{~N}_{3}$ injection-molded magnet with a thickness of $350 \mu \mathrm{m}$ [6].

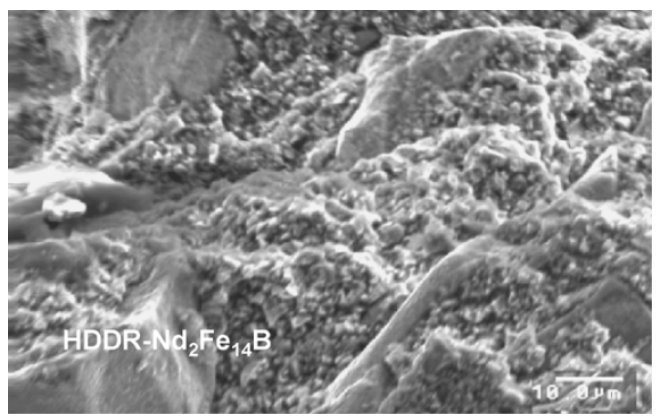

Fig. 6. SEM micrograph of fractured surface of the thinnest rare-earth composite bonded magnet prepared by compaction using the slip-flow phenomenon.

II. The density and $(\mathbf{B H})_{\max }$ were measured by the Archimedes method and with a vibrating sample magnetometer (VSM) after magnetization by a pulsed field of $4 \mathrm{MA} / \mathrm{m}$. The thickness of a composite bonded magnet prepared from compound $\mathrm{I}_{\mathrm{a}}$ can be reduced down to $400 \mu \mathrm{m}$ which is half of the value achieved with compound II. Furthermore, the $(\mathbf{B H})_{\max }$ versus density curve for compound $\mathrm{I}_{a}$ was shifted upward by approximately $10 \mathrm{~kJ} / \mathrm{m}^{3}$ compared with that for compound II. In addition, the $(\mathbf{B H})_{\max }$ value of the magnets prepared from compound $\mathrm{I}_{\mathrm{a}}$ exceeded $140 \mathrm{~kJ} / \mathrm{m}^{3}$ at $5.7 \mathrm{Mg} / \mathrm{m}^{3}$, and was higher than those of the magnets prepared from compound II and 350- $\mu$ m-thick $\mathrm{RD}-\mathrm{Sm}_{2} \mathrm{Fe}_{17} \mathrm{~N}_{3}$ bonded magnets [6].

A scanning electron microscope (SEM) micrograph of the fractured surface of a 400- $\mu$ m-thick composite bonded magnet is shown in Fig. 6. The observed magnet is the thinnest one in the magnets obtained in this study, and the weight ratio of $\mathrm{RD}-\mathrm{Sm}_{2} \mathrm{Fe}_{17} \mathrm{~N}_{3}$ and $\mathrm{HDDR}-\mathrm{Nd}_{2} \mathrm{Fe}_{14} \mathrm{~B}$ included in the magnet is $40 / 60$. As seen in the figure, the isolated structure with $\mathrm{HDDR}-\mathrm{Nd}_{2} \mathrm{Fe}_{14} \mathrm{~B}$ particles and $\mathrm{RD}-\mathrm{Sm}_{2} \mathrm{Fe}_{17} \mathrm{~N}_{3}$ ones and also low compacting pressure suppresses destruction and cracks in $\mathrm{HDDR}-\mathrm{Nd}_{2} \mathrm{Fe}_{14} \mathrm{~B}$ particles are responsible for the improvement of the initial flux loss at elevated temperatures reported previously [2].

The above-mentioned composite bonded magnets as well as hot-deformed rare-earth magnets had a heat and compaction pressure configuration [7], and the control of the shearing stress is an important preparation condition for the alignment

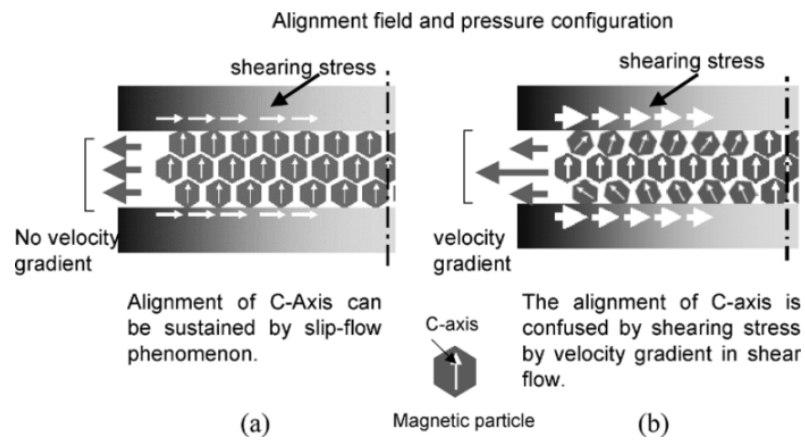

Fig. 7. Schematic representation of alignment of the $C$-axis during the heating and compaction process. (a) Slip-flow phenomenon sustains the alignment of the $\mathrm{C}$-axis. (b) Shear flow disarranges the alignment.

of anisotropic particles. Here, the shearing stress is attributed to velocity gradient during the heating and compaction process.

The use of slip-flow phenomenon reduces the velocity gradient in the compound, and, consequently, the shearing stress between the compound and the punches as shown in Fig. 7(a). Therefore, the alignment of the $C$-axis can be sustained in the magnets prepared from compound $\mathrm{I}_{\mathrm{a}}$. Consequently, the use of the slip-flow phenomenon is a promising method in the preparation of rare-earth composite bonded magnets for transformation into radially anisotropic ones.

\section{CONCLUSION}

The authors found an effective additive (pentaerythritol-stearic-tri-ester) including one hydroxyl group for the solubility to binder and three alkyl groups for the slip-flow during the heating and compaction process, and developed anisotropic thin composite bonded magnets using the slip-flow phenomenon. Consequently, $400-\mu \mathrm{m}$-thick magnets with the (BH) $\max$ value of $140 \mathrm{~kJ} / \mathrm{m}^{3}$ were achieved. Their mechanical strength was enough to transform them into radially anisotropic ones.

\section{REFERENCES}

[1] F. Yamashita, A. Watanabe, and H. Fukunaga, "New preparation method of anisotropic and isotropic Nd-Fe-B flexible bonded magnet for efficient small motors," IEEE Trans. Magn., vol. 39, no. 5, pp. 2980-2982, Sep. 2003.

[2] F. Yamashita, S. Tsutsumi, and H. Fukunaga, "Radially-anisotropic ring/arc-shaped rare-Earth bonded magnets using self-organization technique," IEEE Trans. Magn., vol. 40, no. 4, pp. 2059-2064, Jul. 2004.

[3] F. Yamashita and H. Fukunaga, "Radially-anisotropic rare-earth hybrid magnet with self-organizing binder consolidated under a heat and a lowpressure configuration," in Proc. 18th Int.Workshop High Performance Magnets and Their Applications, Annecy, France, 2004, pp. 76-83.

[4] "Japanese Industrial Standards k-6911," Japanese Standards Association, Tokyo, Japan.

[5] H. Mitarai, Y. Sugiura, H. Matsuoka, and Y. Honkura, "Development of 2-step compression molding for Nd-Fe-B anisotropic bonded magnets," in Proc. 17th Int. Workshop Rare-Earth Magnets and Their Applications, Sendai, Japan, 2000, pp. 787-792.

[6] K. Ohmori, S. Hayashi, and S. Yoshizawa, "Injection molded Sm-Fe-N anisotropic magnets using unsaturated polyester resin," in Proc. RareEarths, Nara, Japan, 2004.

[7] M. Tokunaga, N. Nozawa, K. Iwasaki, M. Endoh, S. Tanigawa, and H. Harada, "Ga added Nd-Fe-B sintered and die-upset magnets," IEEE Trans. Magn., vol. 25, no. 5, pp. 3561-3566, Sep. 1989. 